\title{
PENSANDO O ENSINO DE FÍSICA E O PAPEL DO EDUCADOR DENTRO DO PROJETO "CONEXÃO”
}

\author{
Júlio Cesar Oliveira Garcia ${ }^{1}$ \\ Danilo Seithi Kato ${ }^{2}$
}

\begin{abstract}
RESUMO: Vivência e atuação junto ao projeto CONEXÃO da ONG CIMEAC fomentaram questionamentos a respeito do ensino de Física oferecido neste espaço não formal de educação, bem como do papel do professor e/ou educador atuante neste projeto e em outros semelhantes. Baseado na ideia de que os perfis dos "professores" em projetos educacionais sociais sejam muito semelhantes, e que inúmeras situações do dia a dia sejam recorrentes, busca-se um panorama do ensino de Física dentro destes contextos baseado na literatura específica da área e experiências ao longo de sete anos de atuação junto a este projeto. É de interesse, ao menos a tentativa de, se estabelecer uma distinção e ainda levar a reflexões mais profundas acerca dos papéis do professor e do educador de modo que encontremos a nossa real identidade dentro do projeto contribuindo assim para a sua caracterização completa como um espaço de ensino e criação de conhecimento.
\end{abstract}

PALAVRAS-CHAVE: Ensino de Física; Formação de professores; Espaço não formal de ensino; Educação Popular.

ABSTRACT: Experience and performance in the project CONEXÃO of NGO CIMEAC encouraged questions about the teaching of Physics offered in this non-formal education space, as well as the role of the teacher and/or educator active in this project and other similar. Based on the idea that the profiles of "teachers" in educational projects are very similar, and that many day-to-day situations are recurrent, search an overview of the teaching of Physics within these contexts based on the literature area specific and experiences over seven years of performance together with this project. It is of interest, at least the attempt, make a distinction and also lead to reflections more profound about the roles of the teacher and the teacher's real identity within the project thus contributing to its full characterization as a place of teaching and knowledge creation.

KEYWORDS: Physics education; Teacher's role; Educator; Non-Formal Education; Popular education; Educational Outreach Projects.

\section{INTRODUÇÃO}

A reflexão sobre o ensino de Física de um modo geral deve ser iniciada pensando antes na própria educação, no ato de educar e principalmente no papel que o educador desempenha hoje, em espaços formais e não formais de ensino. As reflexões sobre a prática docente podem estender para a discussão de uma

\footnotetext{
${ }^{1}$ Bacharel em Física Médica pela FFCL/USP, professor e educador nas áreas de Física e Ciências Naturais no ensino fundamental e médio e em instituições de ensino privado no município de Ribeirão Preto. Atua no projeto educacional "Conexão". Contato: julioensinociencias@yahoo.com.br

2 Doutorando em Educação Escolar pela FCL/UNESP. Mestre em Educação na área de Metodologia de Ensino de Ciências e Matemática pela Faculdade de Educação - FEUSP; licenciado em Ciências Biológicas pela Faculdade de Filosofia, Ciências e Letras de Ribeirão Preto- FFCLRP/USP (2003). Atualmente é Educador no Departamento de Biologia da Faculdade de FFCLRP-USP. Possui experiência na área de Educação em Ciências, Educação Ambiental com ênfase em formação de professores.
} 
identidade docente que perpassa o próprio significado do ato de educar. O presente texto não tem o intuito de configurar um ensaio teórico e tem suas reflexões pautadas na análise de um objeto, que são as interações e situações de aprendizagem vivenciadas no curso Conexão. Um espaço não formal de ensino caracterizado pela participação ativa do aprendiz no ato de aprender e no estudo coletivo dos professores voluntários nas preparações de atividades.

O objetivo desse estudo é analisar uma experiência pedagógica no âmbito do ensino de Física em um grupo com características interdisciplinares atuantes em comunidades desfavorecidas socioeconomicamente em um espaço não formal de ensino. A partir dessa análise pretende-se identificar características da formação de professores.

Idealizado e colocado em prática pelos membros da ONG CIMEAC - Centro de Investigações de Metodologias Educacionais Alternativas Conexão, o projeto atende jovens interessados em seu desenvolvimento intelectual a fim de conseguirem o ingresso em universidades, por meio de seus exames vestibulares, ou outras formas de acesso a posições profissionais inacessíveis na maioria das vezes para indivíduos em condições socioeconômicas desfavorecidas.

A vivência em um período de quase sete anos dentro desse projeto proporcionou o questionamento e a reflexão sobre alguns tópicos relacionados à prática docente, o papel do educador e também sobre o ensino de Física.

Dentre os vários questionamentos frutos dessa experiência educacional é possível elencar alguns, os quais considero como os que realmente contribuíram para o momento reflexivo que se desdobrou nesse texto. Primeiramente a busca por uma identidade, como agente individual e também como grupo: Somos educadores ou professores? O que é ser um educador em tempos de globalização e desinteresse das pessoas por este tipo de projeto? Será que o nosso papel ultrapassa as barreiras do mero assistencialismo muito buscado nos dias de hoje e muitas vezes confundido com a missão de projetos como o Conexão?

Em um primeiro olhar os termos educador e professor podem remeter a sinonímia, contudo esse debate traz à tona uma crítica à forma como se diz que deve atuar um professor e como se configura essa ação na realidade escolar brasileira. Portanto, essa diferenciação entre os termos professor e educador provém de uma discussão decorrente da própria ação docente. Por um lado a prática educativa por meio de ações e intervenções que possam promover 
mudanças na perspectiva de vida e na atuação do cidadão em prol a sociedade contemporânea, e por outro lado, uma educação que prioriza o acúmulo de informações e o treinamento para executar funções de forma passiva na sociedade. Portanto, o dilema posto no presente texto vai além da terminologia, mas objetiva discutir a própria profissão e ação docente no sistema escolar atual.

A discussão sobre a profissão docente não é recente e já foi objeto de estudo de diversos pesquisadores (TARDIF, 2002; SACRISTÁN, 1999, 2002; NÓVOA, 1995; entre outros), contudo esse dilema fica mais evidente sob recorte das áreas específicas do ensino. Neste caso, o foco escolhido é o ensino de Física, que poderá materializar a discussão entre o conhecimento científico e a formação cidadã. Qual é o papel do professor de Física, tradicionalmente a resposta é "ensinar Física”. Documentos curriculares oficiais apontam conteúdos conceituais que devem ser priorizados e habilidades e competências a serem desenvolvidas. Contudo, o que observamos é uma restrição do ensino ao conteúdo conceitual focado na memorização de fórmulas, conceitos e cálculos objetivando o treinamento para realização de testes (BEZERRA, 2009).

Essa realidade do chamado professor de Física nos faz pensar sobre lacunas e déficits dessa forma de exercer a profissão professor. Assim, emerge a diferenciação do Educador no sentido de ampliar essa prática. Seria possível compreender os fenômenos físicos por meio de contextos e temas controversos estabelecidos no seio da sociedade? É possível estabelecer situações de aprendizagem em que o conhecimento é o meio pelo qual o cidadão possa analisar criticamente o seu entorno e tomar posição? É possível estabelecer discussões políticas, sociais, culturais, artísticas e científicas na perspectiva do ensino de Física?

Essas questões remetem, como anunciado anteriormente, que a discussão perpassa a dicotomia educador/professor e aponta para o fazer docente. Essa problematização será discutida no presente artigo a partir das experiências em um espaço não formal de ensino denominado Curso Conexão em que os professores planejam atividades a partir de situações controversas reais em sala de aula. $O$ plano de aula compartilhado, a avaliação contínua e os estudos a partir dos conflitos são elementos fundamentais na escolha dessa experiência para analisar o processo formativo do professor/educador do século XXI. 
Somente a partir da reflexão sobre a ação docente em vigência e a ação docente que desejamos é que poderemos pensar o processo formativo. Assim, a presente reflexão vislumbra oferecer apontamentos sobre a formação do professor inicial e em serviço a partir de uma experiência pedagógica.

Buscando a relação entre a prática profissional docente estabelecida no sistema educacional brasileiro e a docência requerida para uma escola democrática e a formação de cidadãos encontramos outros autores que dicotomizam a relação professor/ educador a partir dessa discussão da práticas profissionais. Segundo Marchesi, ser um educador é ser mais do que um professor, mais do que um fornecedor de informações, é se tornar um profissional responsável e preocupado com a própria realidade, um ser que assuma as consequências de seus atos. Implica possuir certas competências, as quais abrangem aspectos morais, emocionais e profissionais. Do ponto de vista profissional cabe aos educadores serem capazes de ensinar e muito mais do que isso, despertar no educando o desejo de aprender. Além disso, o educador deve ser capaz de articular sua aula, ter o domínio sobre os recursos didáticos para que todos aprendam, sem exceções. (MARQUESI, 2007, p. 10-12)

No tocante emocional, educadores e professores devem contribuir para a criação de espaços harmônicos de interações, além é claro de um alto grau de envolvimento com as famílias. Inserida nessa ultima capacidade ou competência cabe ao educador saber e estimular os trabalhos em grupo, para que em equipe seja posto em pratica o processo de criação dessas relações.

Do ponto de vista moral é necessário que haja um compromisso, um contrato, uma responsabilidade com as futuras gerações e com o desenvolvimento do país, além é claro de estar contribuindo para o amadurecimento de virtudes morais e éticas.

Assim, fica evidente que o autor busca uma ampliação do fazer docente para aspectos que vão além do ensino específico do conteúdo conceitual. No entanto, identificamos que esse autor amplia a função docente de forma a perder os limites de um profissional atuante, pois, ao invés de sobrecarregar o professor com funções de ordem psicológica, médica, sociológica e até afetiva, poderia estabelecer melhor a função docente e indicar o trabalho em grupo. Característica que otimiza e amplia o trabalho no processo educativo, sem contudo sobrecarregar ou negligenciar o papel profissional que um professor/educador deva exercer. O Grupo Conexão opta 
pelo trabalho em grupo e o plano pedagógico compartilhado, elementos que somaram na decisão de estudar e refletir essa experiência educacional.

Tardif apresenta o professor educador como "alguém que deve conhecer sua matéria, sua disciplina e seu programa, além de possuir certos conhecimentos relativos às ciências da educação e à pedagogia, é desenvolver um saber prático baseado em sua experiência cotidiana com os alunos" (TARDIF, 2002, p. 39).

Já este autor apresenta uma relação entre os saberes docentes, contudo delimita o território de ação do professor de forma a estabelecer quais são esses saberes sendo o conteúdo conceitual um deles. Contudo, não observamos na perspectiva desse autor de que maneira esses saberes podem se relacionar de forma a configurar o campo de ação desse professor e como mediar o multiculturalismo e as diferenças entre as comunidades de aprendizagem. A experiência analisada nesse artigo tem o objetivo de buscar essa complexidade no entrelaçamento dos saberes docentes em ações educacionais em espaço não formal de ensino. Esse é um ambiente em que professores são voluntários e os estudantes reafirmam a escolha de estar presente, ou seja, não há obrigatoriedade de ambas as partes. Assim espera-se um ambiente em que o discurso dominante do Estado e as regras de gestão do sistema formal de ensino não interfiram no processo de ensino e aprendizagem de forma a proporcionar situações em que dimensões políticos, sociais e culturais emergem juntamente com o conhecimento específico de cada área curricular.

Sacristán (1999) extrapola e ressalta o aspecto cultural da formação dos professores: "a prática pedagógica expressa condutas, crenças, formas de compreensão sobre a função docente, valores compartilhados pelo magistério, que necessitam ser compreendidos", e ainda critica e reforça:

Ninguém pode dar o que não tem. E se os professores não cultivam a cultura, não podem dar cultura. Se os professores não possuem cultura em profundidade, não podem ensinar cultura nem sequer nos níveis mais elementares. $\mathrm{E}$ sobre este princípio elementar há muito pouca investigação. Não tem ocorrido aos pesquisadores analisar os conteúdos culturais dos professores para fazer investigação útil ao professorado. $O$ aspecto prático que se deduz dessa constatação é evidente. Em primeiro lugar, se os professores não são bons profissionais, é preciso que sejam mais bem pagos, melhor considerados e recuperar características de sua profissionalidade. Em segundo lugar, se os professores não podem dar o que não têm, 
é preciso antes de mais nada que sejam cultos, para poderem dar cultura. (SACRISTÁN, 2002)

Para Sacristán a questão política e a gestão são fundamentais para que haja condições de trabalho. Como qualquer outra profissão é necessário infra-estrutura e formação contínua para garantir resultados e eficiência no processo formativo. Não basta ampliar a função do professor e delimitá-la adequadamente se não houver subsídio para que os professores possam alcançar esse "know-how". Assim, a discussão primária desse trabalho torna-se ponto nevrálgico da discussão educacional que qual é a realidade do professor nos sistemas de ensino e como os especialistas, documentos e gestores gostariam que fosse a ação docente.

Pensando um pouco ainda sobre a formação dos professores, Nóvoa (1995, p. 25) nos trás brilhantemente aspectos das experiências e vivências:

A formação não se constrói por acumulação (de cursos, de conhecimentos ou de técnicas), mas sim através de um trabalho de reflexividade crítica sobre as práticas e de (re)construção permanente de uma identidade pessoal. Por isso é tão importante investir a pessoa e dar estatuto ao saber da experiência.

Dessa forma, ser um educador envolve muito mais do que a capacidade de transmissão de conteúdos e controle de sala de aula ou mesmo de domínio de estratégias didáticas, é preciso ser um profissional diferenciado capaz de administrar as adversidades em diferentes contextos, é preciso conhecer a necessidade da capacitação continuada e o processo de vivencia cultural e social. Ser um educador envolve trabalhar múltiplos aspectos da personalidade humana que abarcam desde questões socioculturais até ações e consequências que definem caráter e responsabilidade.

Autores como Tardif, Sácristán, entre outros, delimitam a profissionalidade docente, porém, indicando a importância dessa superação do tecnicismo e o conteudismo (foco nos conteúdos conceituais na ação de ensino) presente na discussão sobre a formação docente. Dessa forma, identificamos que a discussão não é a terminologia Educador/Professor, mas sim a profissionalidade docente. $\mathrm{A}$ superação da ação de ensinar como pré-destinação ou "dom" divino para um arcabouço de saberes, habilidades e competência que possibilitem a intervenção desse profissional no universo social, psicológico e epistêmico dos aprendizes. 
Assim, as experiências educacionais devem proporcionar vivências, interações e dilemas fundamentais na busca de uma formação integral e a profissionalização no sentido de pensar a transformação e a reflexão por meio da educação.

Busca-se nesse texto a reflexão sobre essa prática e as discussões, planejamentos e avaliação aliada aos estudos de autores e obras que discutem outras experiências e ideias do campo educacional. Dessa forma, configura-se o ambiente e condições fundamentais para a formação do professor/educador que possa superar a prática da mera transmissão de informações específicas das áreas do conhecimento.

Não é a intenção apontar uma solução para toda a problemática fomentada no presente artigo, mas sim refletir a questão da ação docente e indicar elementos que possam favorecer o processo formativo do profissional docente que trabalha de forma a dar conta da formação de cidadãos críticos e atuantes e prol de uma sociedade mais justa e democrática, de forma que esse deixe de ser um jargão nos documentos curriculares oficiais e passe para uma realidade no campo da Educação.

\section{O CONTEXTO DE PRODUÇÃO DA ATIVIDADE ANALISADA: O GRUPO CONEXÃO}

O grupo participante do projeto CONEXÃO, formado por profissionais voluntários, carrega consigo certas características como a diversidade de áreas de atuação e formação acadêmica (algumas se destacam como, por exemplo: biólogos, médicos, físicos, químicos, historiadores), além da presença de uma carga evidente de multiculturalismo, credos, crenças, ideias e atitudes. Outra consideração a ser feita é a respeito dos alunos ingressantes no ensino superior que acabam retornando ao projeto para colaborarem de alguma forma. Não menos importante esses profissionais em formação contribuem com o grupo de professores a medida que acrescentam a estes a experiência de ter participado do projeto servindo como uma fonte de críticas e avaliação, bem como um possível exemplo a ser seguido pelos novos cursistas a cada ano.

Todos os professores são voluntários e os estudantes são organizados de maneira a participar ativamente do processo de planejamento, avaliação e gestão do espaço em que as aulas ocorrem. Há o espaço para reuniões semanais em que os 
conflitos, dilemas e dúvidas são compartilhados em grupo de forma a buscar estratégias e ações para cada problema exposto pelo grupo. Diferentemente do espaço formal de ensino, essas características proporcionaram a formação de um coletivo que atua e estuda no sentido de promover uma aprendizagem comprometida com a transformação social do aprendiz, pois a premissa e o fator motivacional da equipe convergem para a falta de acesso daqueles menos favorecidos em nossa sociedade. Essas características favorecerem uma análise mais aprofundada em relação à ação docente, em especifico o ensino de Física, em que os conflitos e os saberes que extrapolam o conteúdo conceitual são evidenciados nas práticas pedagógicas.

Outro ponto que muito contribui para a formação cultural são os encontros realizados entre os membros do grupo intitulados "rompendo as barreiras disciplinares" nos quais os educadores procuram passar o seu ponto de vista dentro de outra disciplina, que não seja a de sua formação, sobre algum assunto de seu interesse. Procura-se sempre expor as suas ideias relacionando tópicos de diferentes áreas do conhecimento, mas que de alguma forma sejam coerentes dentro do assunto.

\section{A PRÁTICA PEDAGÓGICA E O CONHECIMENTO FÍSICO NO CONTEXTO DO CURSO CONEXÃO - A ANÁLISE DA AÇÃO DOCENTE E O ENTRELAÇAMENTO DE SABERES NA CRIAÇÃO DE UMA IDENTIDADE PROFISSIONAL.}

Essa foi uma aula executada por três professores de diferentes áreas do conhecimento, uma matemática, um físico e um biólogo. O contexto de produção da aula era o tema Energia em que todas as atividades do mês discutiam a questão energética, a tecnologia e a sociedade. O desafio era trazer questões relacionadas ao tema polêmico das matrizes energéticas. O grupo de professores preconizava uma situação de aprendizagem em que os aprendizes pudessem participar ativamente da discussão. Dessa forma, a ideia foi a criação de um jogo cuja descrição do mesmo encontra-se a seguir:

Os participantes receberam o manual de instruções com as regras do "jogo da energia", que consiste, basicamente, em atribuir a cada bioma uma matriz energética, levando em consideração as características físicas, sociais e 
econômicas de cada local. Em seguida, cada equipe elegia um representante para ser a peça a se mover no tabuleiro que fora construído no chão da sala de aula.

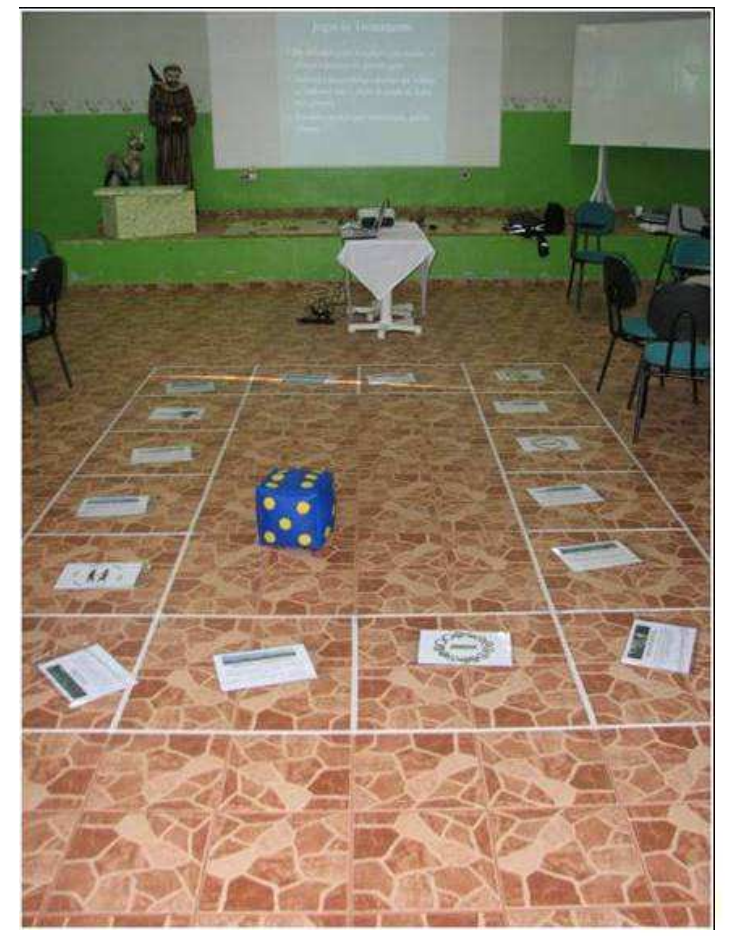

Figura 1 - Tabuleiro do Jogo riscado no chão com fita adesiva. Fonte: Acervo Pessoal

O jogo é composto por um tabuleiro com 22 casas, em que uma peça indica o início e as 21 casas restantes estão divididas da seguinte maneira:

- Casas de biomas: Amazônia, Mata Atlântica, Cerrado, Zona Costeira, Caatinga, Campos Sulinos, Cerrado-Caatinga, AmazôniaCaatinga, Amazônia-Cerrado e Cerrado-Caatinga, sendo essas quatro últimas consideradas como zonas de transição.

- Quatro casas de sorte ou de catástrofe (revés): os cartões que correspondem a essas casas são sorteados aleatoriamente, podendo beneficiar ou prejudicar as equipes que se enquadram na situação do cartão.

- Duas casas de leilão: a equipe que ocupar essas casas poderá propor compra e venda de biomas já ocupados com valores aleatórios.

- Uma casa de black out: o jogador que ocupar essa casa deve permanecer sem jogar na próxima rodada.

- Três casas de transação: a equipe que ocupar essa casa poderá propor compra ou venda dos biomas já ocupados. Essas negociações deverão respeitar o valor estipulado no cartão.

- Uma casa de recarga: a equipe que ocupa essa casa ganha 100 pontos e joga novamente.

Ao ocupar uma casa referente a um bioma, cabia ao grupo optar por comprálo (devendo escolher uma das matrizes energéticas para vigorar no local) ou não 
(dessa forma, pagaria a taxa de passagem e seguiria o jogo). Além disso, havia a possibilidade de instalar indústrias em outros biomas, o que fez os grupos refletirem sobre os possíveis impactos ambientais dessas ações.

Outras casas do tabuleiro traziam um fenômeno físico ou social (sorte ou catástrofe) que poderia beneficiar ou prejudicar os grupos. Traziam, também, um bônus (recarga) em pontos de energia e uma punição (black-out).

A equipe que não tivesse sorte de ocupar muitos biomas poderia tentar comprar biomas de outras equipes por meio das casas de transação (respeitando os valores pré-estipulados) ou leilão (ficando livre para propostas e valores).

As equipes podem ser formadas de um a seis jogadores, representadas por cores diferentes. Assim, cada jogada será determinada por um dado de seis faces, de forma que a face superior determinará a quantidade de casas que cada equipe deverá andar naquela vez.

Cada equipe iniciará com certa quantidade de pontos de energia, de maneira que é recomendado que se utilizem valores de 2.000 a 5.000 pontos, dependendo do número de equipes ou jogadores participantes. É importante ressaltar que cada uma das casas de biomas possui cartões com características e informações relevantes ao bioma.

É válido salientar que, para auxiliar as informações ao longo do jogo, se devem utilizar uma apresentação em PowerPoint (podendo ser substituída por um arquivo impresso que contenha as informações dos slides) e, também, uma planilha de dados (aplicativo Excel) para a contagem dos pontos de energia. Esse controle poderá ser feito por um membro de cada equipe. Caso não seja possível ter esses recursos, recomenda-se o uso da planilha impressa.

Após 20 rodadas, o jogo foi encerrado, de modo que os alunos, então, foram convidados para uma reflexão a respeito das estratégias do jogo e das decisões de cada equipe no ponto de vista ambiental. Foi

a
oportunidade para que

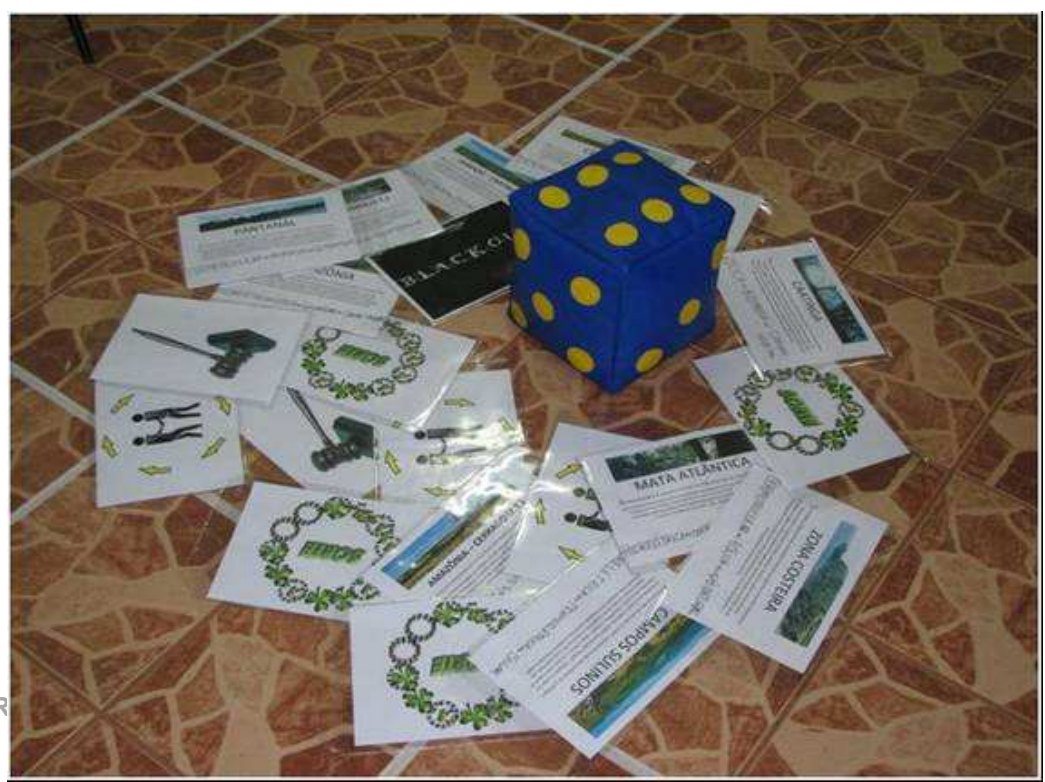


todos pudessem justificar suas ações.

Figura 2 - Materiais utilizados no jogo de tabuleiro. Fonte: acervo pessoal.

Completou-se a oficina com uma breve teoria sobre o uso do jogo em sala de aula, chamando a atenção do professor para as formas de explorar esse recurso didático para introduzir, desenvolver ou concluir um conteúdo. Desse modo, foram levantados os pontos importantes no desenvolvimento sociocognitivo que o jogo bem planejado pode oferecer aos alunos.

\section{RESULTADOS}

O debate e a vivência relacionados ao tema proporcionaram uma reflexão sobre uma leitura sistêmica e complexa do meio ambiente. Dessa forma, as concepções sobre as relações causais entre homem e ambiente puderam ser reconsideradas por essa maneira de encarar a relação matéria-energia e meio ambiente.

A atividade foi realizada em dois encontros, nos quais foram priorizadas as discussões sobre os impactos ambientais e a influência da energia nesse contexto. Os grupos foram acompanhados em suas propostas sobre o tema. No processo, surgiram ideias e discussões que evidenciavam o uso de conceitos da Física inseridos na problemática ambiental.

\section{AS CASAS DE BIOMAS}

O jogador que ocupava a casa correspondente a um bioma teve a opção de assumir o seu controle e decidir, com a equipe, qual a matriz energética irá explorar e utilizar para a geração de energia daquele local.

Cada bioma apresentava três opções de matrizes energéticas distribuídas segundo as características da região, levando em consideração aspectos socioeconômicos, transporte, tecnologia e possíveis impactos ambientais que essas matrizes podem causar. Essas informações são encontradas em livros didáticos de Geografia e sites especializados.

Além disso, cada uma das matrizes energéticas tinha um preço a ser pago para o banco de energia, e estas foram apresentadas em PowerPoint após a escolha de cada equipe. Os preços serão definidos segundo a viabilidade da 
construção e manutenção, bem como a utilização dos recursos energéticos proporcionados pelas matrizes energéticas.

Ao cair em uma casa bioma, o jogador fazia a leitura em voz alta a descrição feita no cartão, com o objetivo de que todos os participantes saibam como são as características de cada bioma. Se o jogador optar por não assumir o controle do bioma, a equipe passará por ele e pagará apenas uma taxa de passagem ao banco de energia, que tinha valor fixo de 50 pontos. Caso o bioma já possuía um administrador, a equipe poderá optar por desenvolvê-lo com a construção de um empreendimento industrial (cujo valor estará explícito no arquivo impresso referente aos biomas ou na apresentação de PowerPoint no momento de aquisição do bioma pela equipe que o controla) que contribua para o desenvolvimento da região em questão.

É valido salientar que cada setor industrial possui um valor para a construção de acordo com a matriz energética produtora de energia naquele bioma. Caso seja decidido não desenvolver nenhum empreendimento, será paga apenas a "taxa de passagem" para o administrador do bioma e para o administrador do empreendimento industrial, caso este já tenha sido construído naquele bioma. $A$ construção de empreendimentos foi limitada ao número de dois estabelecimentos industriais por bioma. Caso o bioma já possua os dois empreendimentos construídos, a equipe deverá pagar, obrigatoriamente, a "taxa de passagem" ao administrador do bioma e aos administradores dos empreendimentos já instalados. O desenvolvimento por meio dos empreendimentos só é possível após a ocupação do bioma e instalação da matriz energética que irá suprir de energia os estabelecimentos.

\section{AS CASAS DE "SORTE” OU DE "REVÉS”}

As casas de "sorte" ou de "revés" possuíam situações diversas de sorte ou de catástrofes, contextualizadas aos tipos de matrizes energéticas do jogo. Ao ocupar uma dessas casas, um membro da equipe deverá tirar ao acaso um cartão do monte "sorte/catástrofes", que estava no meio do tabuleiro ou foi fornecido pelos professores.

As informações desses cartões afetavam todas as equipes que possuírem a matriz energética referida no cartão, pois podem ser boas (e, nesse caso, as equipes ganham pontos de energia) ou ruins (cabendo às equipes pagarem alguns 
pontos de energia). Poderá ocorrer, ainda, o caso (principalmente no início do jogo) de nenhuma equipe sofrer as consequências desses cartões.

\section{AS CASAS DE “LEILÃO”}

As casas de "leilão" possuíam função de iniciar um leilão dos bens (biomas e indústrias) que cada equipe possuía. A equipe interessada em vender seu próprio bioma ou comprar algum outro já ocupado estipula o preço dos bens, oferecendo-os aos outros jogadores por meio de lances e ofertas segundo a conveniência de cada equipe.

\section{AS CASAS DE "TRANSAÇÃO"}

As casas de "transação" possuíam a função de iniciar, como o próprio nome já diz, uma transação de bens (biomas e indústrias) que cada equipe possui. Nesse caso, os preços são fixados segundo o tipo de matriz energética do bioma e estabelecidos previamente.

\section{A CASA DE BLACK-OUT E DE RECARGA}

A casa de "black-out" servia para bloquear o movimento dos jogadores, de maneira que, se estes a ocuparem, ficarão sem jogar durante uma rodada completa.

Já a casa de "recarga" beneficia os jogadores que a ocuparem com 100 pontos de energia extras, além de dar o direito de a equipe jogar o dado novamente.

\section{FALÊNCIA}

Quando o jogador não possuía mais pontos e ainda tivesse algum bioma sob seu controle, ele deveria esperar (sem jogar) alguém que esteja na casa de transação ou de leilão para tentar, por meio de acordos, conseguir pontos para pagar o que deve. Caso não possua mais nenhum desenvolvimento, ele estará fora da partida.

O jogo descrito apresenta uma forma alternativa de aprendizagem, que no caso da Física a torna mais acessível à medida que parte do cotidiano e de problemas socioambientais reais em que os estudantes representam papéis e são forçados a tomar posição frente à problemática. Neste caso, o jogo, o contexto e o tema controverso, e o contexto do grupo Conexão favoreceram a observação das 
interações entre professor e os aprendizes de modo a analisar de forma mais próxima a ação do professor de Física e seu papel nesse contexto descrito.

O ensino de Física pode partir de uma curiosidade sobre objetos e processos, de uma observação dos fenômenos, ou ainda, por estímulos vindos de diversas fontes como redes sociais, grupos de estudo e jogos e outros contextos educacionais. Contudo, percebe-se que o eixo fundamental na pró-atividade de manipular saberes, entre eles o conhecimento físico, é a utilização do tema controverso na sala de aula (SILVA; CARVALHO, 2007).

Dessa forma, o jogo e o dispositivo didático proporciona o envolvimento do aprendiz com o objeto de aprendizagem, contudo é o tema polêmico e o desafio real colocado no funcionamento da sociedade que mobiliza os conhecimentos físicos para a resolução dos problemas ao longo da atividade.

No âmbito das instituições ressalta-se que as escolas se configuram como espaços fundamentais para a disseminação desse conhecimento além de servir como fonte de motivação e estimulo à aprendizagem. Ainda relacionado encontramos os espaços de educação não formal como museus, bibliotecas e projetos sociais educacionais entre outros que procuram romper com a forma tradicional de ensino focada na transmissão e memorização de conceitos e regras.

O discurso ambientalista e o discurso escolar se aproximam no contexto de aprendizagem em que a decisão sobre uma matriz energética e a sustentabilidade econômica. Silva e Carvalho (2007) observam que a crítica ao ensino de Física concentra-se na sua abordagem extremamente conceitual e factual não ampliando o contexto e conflitos socioambientais nas discussões em sala de aula. Há a ênfase em descrições matemáticas dos fenômenos em detrimento de um posicionamento crítico frente as situações concretas vivenciadas pelo aprendiz.

A prática do professor de Física restringe-se aos aspectos técnicos dos conteúdos escolares conceituais deixando de lado aspectos procedimentais e atitudinais que são fundamentais para a formação de um cidadão que participa das discussões coletivas de sua sociedade. Contudo, nota-se que para estabelecer atividades de ensino contrárias a essa realidade é necessário um professor com algumas características peculiares que retomam nossa discussão sobre o papel do professores/educador.

Nessa experiência pedagógica observa-se que o poder criativo e a autoria dos professores que trabalham juntos e de áreas distintas convergiram no tema 
controverso e na problemática para a elaboração do jogo e da atividade de ensino como um todo. Não seria possível vivenciar essa situação de aprendizagem sem a discussão real do problema pelos professores de diferentes áreas que por meio de seu conhecimento específico poderia imaginar a ação de aprender Física, Biologia e Matemática a partir da resolução de problemas e do envolvimento com o tema controverso tomando posição frente às demandas hipotéticas surgidas durante a prática.

A avaliação e a discussão das decisões e estratégias evidenciaram a reflexão do estudante perante suas ações em grupo, bem como individuais. Nesse momento o professor retoma os conhecimentos específicos, neste caso os conceitos de energia e matriz energética, que foram utilizados como meios para resolver o problema ou tomar decisões. A partir desse conhecimento é estabelecida a discussão sobre os efeitos dessas decisões para o meio ambiente e para a sociedade trazendo uma dimensão ética para o discurso pedagógico estabelecido em sala de aula.

Assim é possível concluir que o dialogismo entre professores e aprendizes, e entre os próprios aprendizes requer uma situação de aprendizagem que permita a circulação das diferentes vozes. O entrelaçamento dos discursos e a discordância das situações vivenciadas promovem o desenvolvimento da habilidade argumentar e discutir ciência. Fator fundamental para um cidadão que saiba se comunicar cientificamente.

Contudo, a ação do professor, neste caso, implica um profissional que domina o conteúdo se sua própria disciplina, mas também domina saberes relacionados às temáticas concretas postas na sociedade, mediando uma discussão que possa colocar o sujeito em condição ativa perante as questões. Para isso, o professor precisa preocupar-se com outros saberes relacionados a sociologia, antropologia, filosofia e outras áreas do conhecimento que proporcionem uma visão ampliada e a possibilidade de constituir temas controversos para a sala de aula. Assim o trabalho em grupo e a busca pela interdisciplinaridade tornam-se condição sine qua non para uma formação reflexiva preconizando o professor como um intelectual crítico (GIROUX, 1997). 


\section{CONSIDERAÇÕES FINAIS}

Dentro do projeto CONEXÃO a realidade se faz um pouco diferente e a pergunta que surge é "Como ensinar Física para um grupo sócio economicamente desfavorecido"? Neste ponto podemos retomar a questão do papel do educador.

Ser um educador nessas condições é exercer o papel real desta função. É necessário ser educador e não apenas professor. Faz-se necessário ter a preocupação com a qualidade do ensino e do estudo, das aulas à infraestrutura; aprofundando o tema no ensino de Física, observa-se a característica de o grupo docente ser formado por pessoas dispostas, que sentam, planejam e principalmente dialogam e estudam em conjunto como modus operandi de uma "profissionalidade". Essa é a identidade docente necessária para balizar programas e centros de formação de professores.

Não se prioriza na Física a coleção de teorias, formulas e cálculos, mas tópicos relacionados à historia das Ciências, à biografia dos principais representantes bem como ao uso da experimentação como mola propulsora de uma aprendizagem mais concreta.

Outras experiências nesse sentido, dentro das outras áreas do conhecimento, ocorreram na forma de eventos promovidos pelos membros e que se configuraram como atividades pedagógicas dentro dos módulos. A SEAC - Semana de arte e Cultura e a SETEC - Semana de Tecnologia e Ciências foram momentos estimulados e realizados nos quais os alunos deixaram um pouco a sistemática normal das aulas e passaram a ter contato com aspectos culturais e científicos de nossa sociedade.

Nesse contexto, muitas vezes sem que percebam, adquirem o conhecimento tanto quanto, senão de forma mais completa do que se estivessem em uma aula normal do projeto. De certa forma é possível notar que os educadores do projeto Conexão valorizam as relações de amizade construídas entre eles e também as relações construídas com os educandos. O exercício da autorreflexão e a crítica à própria identidade no sentido de estimular o estudo sobre as práticas adotadas e promover melhoras no gerenciamento do próprio projeto é uma ação rotineira. Sendo assim as premissas de Nóvoa (1995, p. 25) estão brilhantemente estabelecidas a medida que descrevem bem o processo vivido dentro desse projeto "[...] a formação se da através de um trabalho de reflexividade critica sobre as práticas e de reconstrução permanente de uma identidade". 


\section{REFERÊNCIAS BIBLIOGRÁFICAS}

BEZERRA, D. P.; GOMES, E. C. S.; MELO, E. S. N.; SOUZA, T. C. A evolução do ensino da física - perspectiva docente. Scientia Plena, Aracaju, v. 5, n. 9, 2009.

GIROUX, H. A. Os professores como intelectuais: rumo a uma pedagogia crítica da aprendizagem. 2 ed. Porto Alegre: Editora Penso, 1997.

MARCHESI, A. Valores e competências do educador. Revista linha direta: educação por escrito, Belo Horizonte, v. 10, n. 117, p. 10-12, dez/2007.

NEVES, M. C. D. Memórias do invisível: uma reflexão sobre a história no ensino de física e a ética da ciência. Maringá: LCV edições, 1999.

NÓVOA, A. (Coord.). Os professores e a sua formação. 2 ed. Lisboa: Dom Quixote, 1995.

SACRISTÁN, J. G. Poderes instáveis em educação. Trad. Beatriz Affonso Neves. Porto Alegre: Artes Médicas do Sul, 1999.

- Tendências investigativas na formação de professores. Revista da Faculdade de Educação - UFG, 27 (2): 1-54, jul./dez. 2002.

SILVA, L. F.; CARVALHO, L. M. A temática ambiental e o processo educativo: o ensino de Física a partir de temas controversos. Ciência \& Ensino, Campinas, v. 1, n. especial, nov. 2007.

TARDIF, M. Saberes docentes e formação profissional. Petrópolis, RJ: Vozes, 2002. 